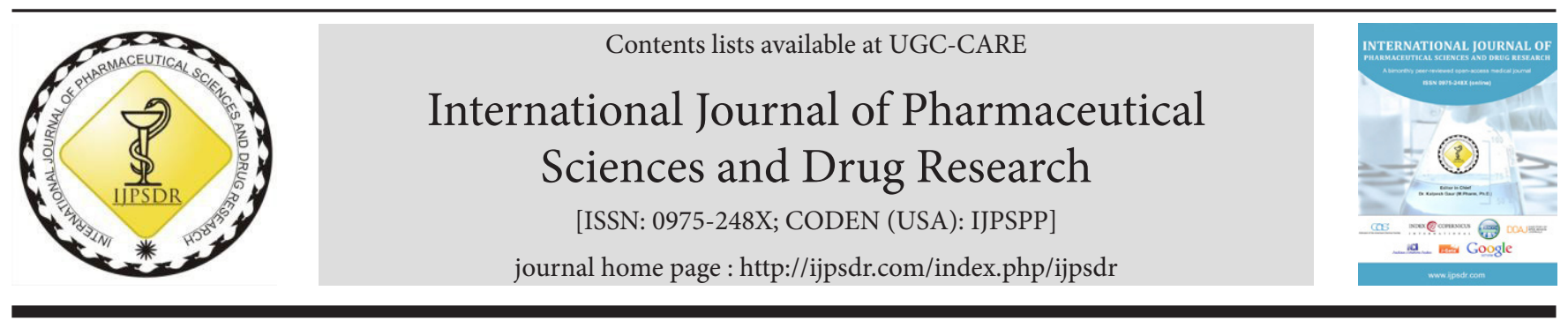

Research Article

\title{
Synthesis and Evaluation of 7-(2-((Substituted Phenyl) Imino)-2- Phenylethoxy)-4-Methyl-2H-Chromen-2-Ones as Antifungal Agents
}

\author{
Mohit Gupta $^{1^{*}}$, Sushil Kumar ${ }^{2}$ \\ ${ }^{1}$ Shri Ram Murti Smarak College of Engineering \& Technology, Bareilly (Pharmacy), Bareilly-243202, Uttar Pradesh, India \\ ${ }^{2}$ School of Pharmaceutical Sciences, IFTM University, Moradabad-244001, Uttar Pradesh, India
}

\author{
A R T I C L E I N F O \\ Article history: \\ Received: 08 January, 2020 \\ Revised: 18 April, 2020 \\ Accepted: 25 April, 2020 \\ Published: 30 May, 2020 \\ Keywords: \\ Candida albicans, \\ Chromen-2-ones, \\ Molecular properties, Schiff base. \\ DOI: \\ 10.25004/IJPSDR.2020.120302
}

\begin{abstract}
A B S T R A C T
In the context of the dangerous phenomenon of antimicrobial resistance to the available drugs, we present here the synthesis and evaluation of 7-(2-((substituted phenyl) imino)-2-phenylethoxy)-4-methyl-2Hchromen-2-ones as antifungal agents. Among the compounds, SB-4 was found to be most potent against Candida albicans, when compared with the reference drugs clotrimazole and terbinafine. The molecular properties of the new target compounds were performed by online software, and results showed good drug-like properties. The results showed target compounds further optimized as lead compounds as anti-Candida potential.
\end{abstract}

\section{INTRODUCTION}

Schiff bases are the key intermediates, also common ligands, in the organic synthesis and have been shown to exhibit a broad range of biological activities, including antimicrobial, antiviral, anthelmintic, antiproliferative, and antioxidant. ${ }^{[1-8]}$ The imine group present in such compounds has been shown to be essential for their biological activities. Clotrimazole and terbinafine are the antifungal drugs containing nitrogen hetero atom into their structures. The ample evidence reported in the literature on the biological potential of Schiff bases containing $\mathrm{C}=\mathrm{N}$ in their structure ${ }^{[9,10]}$ led us to the synthesis, physicochemical characterization, and antifungal evaluation of new Schiff bases containing nitrogen heteroatom. The pharmacokinetic and pharmacodynamic behavior of molecules inside the human body is influenced by their molecular properties, molecular size, flexibility, and the presence of different pharmacophore features. The in vivo experimental determination of pharmacokinetic parameters of newly synthesized compounds is uneconomical and timeconsuming. From this point of view, molecular properties can predict by the online software. ${ }^{[11]}$ The molecular properties of the new compounds could help to eliminate the molecules likely to fail in the early stage of drug discovery. In view of these observations, we herein report the synthesis and evaluation of new Schiff bases as antifungal agents.

\section{Material And Methods}

Melting points of the synthesized compounds were determined by the open capillary method and are

\footnotetext{
${ }^{*}$ Corresponding Author: Dr. Mohit Gupta

Address: Shri Ram Murti Smarak College of Engineering \& Technology, Bareilly (Pharmacy), Bareilly-243202, Uttar Pradesh, India

Email $\square$ : drmohit.mpharmphd@gmail.com

Tel.: +91-9358211655

Relevant conflicts of interest/financial disclosures: The authors declare that the research was conducted in the absence of any commercial or financial relationships that could be construed as a potential conflict of interest.

Copyright (C) 2020 Mohit Gupta et al. This is an open access article distributed under the terms of the Creative Commons Attribution- NonCommercialShareAlike 4.0 International License which allows others to remix, tweak, and build upon the work non-commercially, as long as the author is credited and the new creations are licensed under the identical terms.
} 
uncorrected. The infrared spectroscopy (IR) spectra of synthesized compounds were recorded in potassium bromide discs on the Nicolet iS5 FTIR spectrophotometer. The ${ }^{1} \mathrm{H}$ NMR spectra were recorded on a Bruker DRX spectrophotometer at $400 \mathrm{MHz}$ in $\mathrm{CDCl}_{3}$ and $\mathrm{DMSO}$, containing TMS as an internal standard. All chemical shift values are reported in ppm $(\delta)$. The reactions progress was monitored by thin-layer chromatography (TLC) using silica gel $\mathrm{G}$, and spots were visualized in an iodine chamber.

\section{Experimental}

Synthesis of 4-Methyl-7-(2-Oxo-2-Phenylethoxy)-2HChromen-2-One (3)

Equimolar amounts of 2-bromo-1-phenylethanone 1 (0.01 mol), 7-hydroxy-4-methylcoumarin 2 (0.01 mol), and anhydrous $\mathrm{K}_{2} \mathrm{CO}_{3}(0.02 \mathrm{~mol})$ in dry acetonitrile were refluxed for about 8 hours. The mixture was filtered, and the solvent was removed under reduced pressure. The resulting solid was washed with aqueous sodium hydroxide solution (20\%) and with an excess of water. The crude product was purified by recrystallization from ethanol to afford compound 3. Yield: 55.0\%; M.P.: 138 to $140^{\circ} \mathrm{C} ; \mathrm{R}_{\mathrm{f}}: 0.86$ (n-hexane:ethyl acetate; $1: 2$ ).

General Procedure for the Synthesis of 7-(2-((Substituted Phenyl) Imino)-2-Phenylethoxy)-4-Methyl-2H-Chromen-2Ones ( $S B-1$ to $S B-16)$

Compound 3 (0.01 mol), substituted aniline 4 (0.01 mol), $1 \mathrm{~mL}$ of glacial acetic acid was dissolved in methanol (100 $\mathrm{mL})$, and the reaction mixture was refluxed on the water bath for 12 hours. The solution was allowed to cool, and then, the separated solid was washed with water, filtered, and recrystallized from methanol to afford the target compounds SB-1 to SB-16.

\section{Molecular Properties Prediction of SB-1 to SB-16}

A set of molecular properties molar refractivity, topological surface area, and $\log \mathrm{P}$ were computed for the target compounds, as well as, two standard drugs clotrimazole and terbinafine use Chem 3D Ultra version 12.0 software programs. The observations are depicted in Table 1.

\section{Antimicrobial Activity}

The antifungal testing was performed using the cup diffusion technique. The synthesized compounds, as $1 \mathrm{mg} / \mathrm{mL}$ solutions in dimethylformamide (DMF), were evaluated in vitro for activity against $C$. albicans by the cup diffusion technique. ${ }^{[12]}$ Compounds showing inhibitory zones of at least $20 \mathrm{~mm}$ were considered active and were further evaluated for their minimal inhibitory concentration (MIC), using the two-fold serial dilution method. ${ }^{[13]}$ Clotrimazole and terbinafine were used as standard antifungal agents. DMF was used as a control. The sterile nutrient agar was inoculated with the test organisms (each $100 \mathrm{~mL}$ of the medium received $1 \mathrm{~mL}$ of 24 hours broth culture), and then seeded agar was poured into sterile Petri dishes. Cups (8 $\mathrm{mm}$ in diameter) were cut in the agar, and each cup received $0.1 \mathrm{~mL}$ of the test compound solution. The plates were then incubated at $37^{\circ} \mathrm{C}$ for 24 hours. The activities were estimated as zones of inhibition in mm diameter (Table 2). Clotrimazole and terbinafine solutions $(0.01 \%)$ were used as reference standards. DMF did not show any inhibition zones.

\section{Minimum Inhibitory Concentration (MIC) Measurement}

Using the two-fold serial dilution method, the test organisms were grown in suitable broth for 48 hours for fungi at $37^{\circ} \mathrm{C}$. Two-fold serial dilutions of the test compound solutions were prepared using the suitable broth to obtain concentrations between 1,000 and $15.62 \mu \mathrm{g} / \mathrm{mL}$. The tubes were then inoculated with the test organism (each $5 \mathrm{~mL}$ received $0.1 \mathrm{~mL}$ of the above inoculums), and were incubated at $37^{\circ} \mathrm{C}$ for 48 hours. The tubes were then observed in the presence or absence of microbial growth. The lowest concentration showing no growth was taken as the minimum inhibitory concentration. The MIC values of the prepared compounds are listed in Table 2.

\section{RESULTS AND DISCUSSION}

The target compounds SB-1 to SB-16 were prepared as outlined in scheme 1. The 2-bromo-1-phenylethanone (1) (0.01mol), 7-hydroxy-4-methylcoumarin (2) (0.01 mol), and $\mathrm{K}_{2} \mathrm{CO}_{3}(0.02 \mathrm{~mol})$ in dry acetonitrile was refluxed for

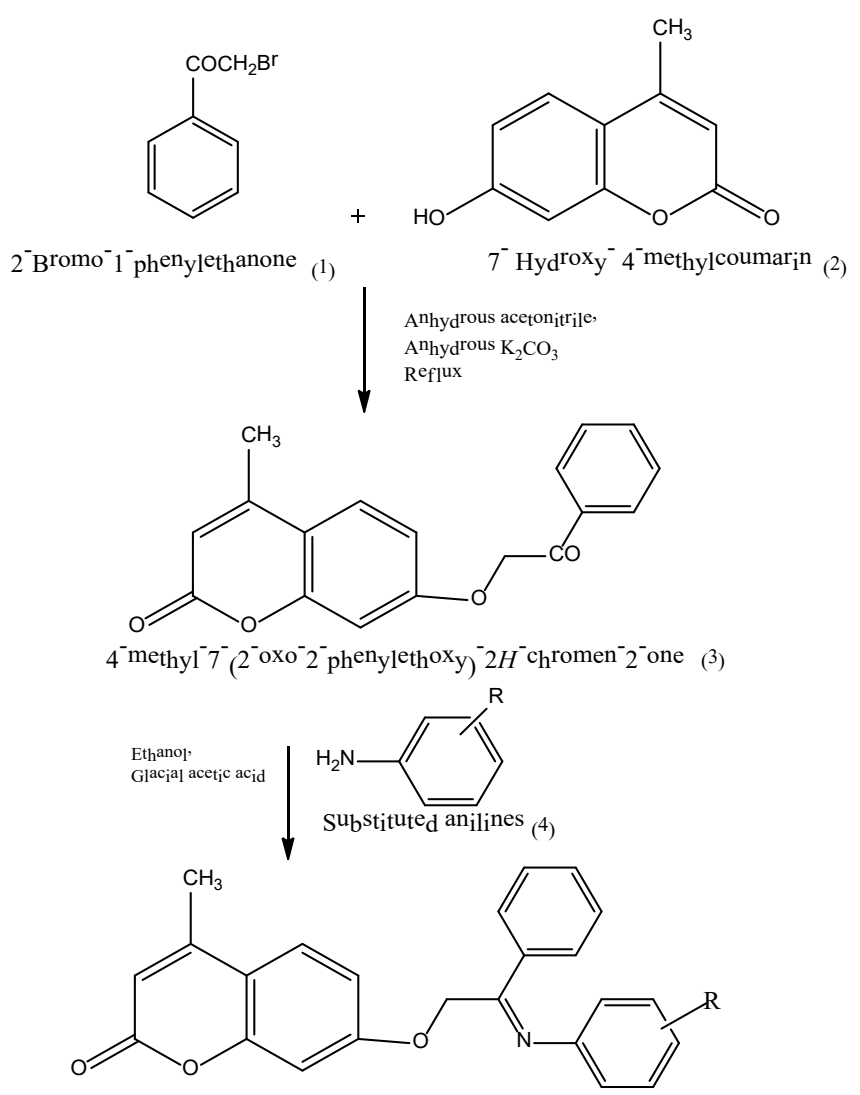

Fig. 1: Synthesis of target compounds (SB-1 to SB-16) 
Synthesis and Evaluation of Chromen-2-Ones as Antifungal Agents.

Table 1: Molecular properties of SB-1 to SB-16

\begin{tabular}{|c|c|c|c|c|c|c|c|c|c|c|c|}
\hline $\begin{array}{l}\text { Compound } \\
\text { code }\end{array}$ & $R$ & $M W^{a}$ & $M R^{b}$ & $t P S A^{c}$ & $\begin{array}{l}S A S^{d} \\
\left(A^{2}\right)\end{array}$ & $\begin{array}{l}M S A^{e} \\
\left(A^{2}\right)\end{array}$ & $\begin{array}{l}S E V^{f} \\
\left(A^{3}\right)\end{array}$ & $M T I^{g}$ & $W I^{h}$ & $O v^{i}$ & $\log P$ \\
\hline SB-1 & $\mathrm{H}$ & 369.41 & 110.64 & 47.89 & 600.78 & 319.53 & 277.42 & 16,633 & 2,183 & 1.550 & 4.91 \\
\hline SB-2 & $4-\mathrm{CH}_{3}$ & 383.44 & 116.54 & 47.87 & 620.54 & 335.65 & 296.12 & 18,448 & 2,418 & 1.562 & 5.4 \\
\hline SB-3 & $4-\mathrm{Cl}$ & 403.86 & 115.24 & 47.87 & 616.36 & 332.89 & 292.78 & 17,740 & 2,418 & 1.561 & 5.47 \\
\hline SB-4 & $4-\mathrm{Br}$ & 448.31 & 118.33 & 47.89 & 621.61 & 337.54 & 298.96 & 17,740 & 2,418 & 1.561 & 5.74 \\
\hline SB-5 & $3,4-\mathrm{Cl}$ & 438.3 & 119.85 & 47.89 & 636.61 & 346.18 & 306.86 & 18,750 & 2,634 & 1.573 & 6.03 \\
\hline SB-6 & $2-\mathrm{NO}_{2}$ & 414.41 & $\mathrm{NC}$ & 99.7 & 600.7 & 319.49 & 277.51 & 20,415 & 2,816 & 1.552 & 4.22 \\
\hline SB-7 & $3-\mathrm{Cl}$ & 403.86 & 115.85 & 47.89 & 625.33 & 334.36 & 291.77 & 17,637 & 2,396 & 1.571 & 5.47 \\
\hline SB-8 & $4-\mathrm{NO}_{2}$ & 414.41 & $\mathrm{NC}$ & 99.7 & 618.7 & 336.02 & 296.34 & 21,209 & 2,948 & 1.563 & 4.27 \\
\hline SB-9 & $4-\mathrm{OCH}_{3}$ & 399.44 & 117.89 & 57.12 & 620.89 & 337.83 & 300.02 & 20,012 & 2,682 & 1.587 & 4.79 \\
\hline SB-10 & $2-\mathrm{Cl}$ & 403.86 & 115.24 & 47.89 & 600.39 & 319.44 & 278.55 & 17,534 & 2,374 & 1.548 & 4.57 \\
\hline SB-11 & $\begin{array}{l}2-\mathrm{Cl}, \\
4-\mathrm{NO}_{2}\end{array}$ & 448.86 & 121.14 & 47.89 & 618.3 & 335.92 & 297.46 & 22,155 & 3,153 & 1.558 & 5.96 \\
\hline SB-12 & $3-\mathrm{NO}_{2}$ & 414.41 & 414.41 & 99.7 & 600.27 & 321.94 & 283.23 & 20,812 & 2,882 & 1.543 & 4.22 \\
\hline SB-13 & $2-\mathrm{Br}$ & 448.31 & 448.31 & 47.89 & 600.39 & 319.55 & 279.55 & 17,534 & 2,374 & 1.545 & 5.74 \\
\hline SB-14 & $4-\mathrm{F}$ & 387.4 & 387.4 & 47.89 & 604.73 & 322.86 & 280.9 & 17,740 & 2,418 & 1.556 & 5.07 \\
\hline SB-15 & $2-\mathrm{OCH}_{3}$ & 399.44 & 399.44 & 57.12 & 599.4 & 319.49 & 281.57 & 19,424 & 2,594 & 1.537 & 4.79 \\
\hline SB-16 & $2-\mathrm{CH}_{3}$ & 383.44 & 383.44 & 47.89 & 601.55 & 320.58 & 280.66 & 18,110 & 2,374 & 1.546 & 5.4 \\
\hline Clotrimazole & & 344.82 & 102.07 & 15.6 & 540.05 & 284.92 & 270.21 & 9,498 & 1,225 & 1.409 & 5.19 \\
\hline Terbinafine & & 291.43 & 99.36 & 3.24 & 596.56 & 311.07 & 265.26 & 10,280 & 1,273 & 1.558 & 5.52 \\
\hline
\end{tabular}

Abbreviations: ${ }^{\mathrm{a}}$ molecular weight; ${ }^{\mathrm{b}}$ molar refractivity; ${ }^{\mathrm{c}}$ topological polar surface area; ${ }^{\mathrm{d}}$ Connolly solvent accessible surface area; ${ }^{\mathrm{e} C o n n o l l y}$ molecular surface area; ${ }^{\mathrm{f} C o n n o l l y ~ s o l v e n t ~ e x c l u d e d ~ v o l u m e ; ~}{ }^{\mathrm{g}}$ molecular topological index; ${ }^{\mathrm{h}}$ Wienner index; ${ }^{\mathrm{i}}$ ovality; $\mathrm{NC}=$ not calculated

Table 2: The antifungal activity of Schiff bases (SB-1 to SB-16)

\begin{tabular}{|c|c|c|c|}
\hline $\begin{array}{l}\text { Compound } \\
\text { code }\end{array}$ & $R$ & $\begin{array}{l}\text { Zone of inhibition } \\
\text { (in mm) against } \\
\text { C. albicans }\end{array}$ & $\begin{array}{l}\text { MIC }(\mu \mathrm{g} / \mathrm{mL}) \\
\text { against } \\
\text { C. albicans }\end{array}$ \\
\hline SB-1 & $\mathrm{H}$ & 20 & 31.24 \\
\hline SB-2 & $4-\mathrm{CH}_{3}$ & 14 & NC \\
\hline SB-3 & 4-Cl & 20 & 31.24 \\
\hline SB-4 & $4-\mathrm{Br}$ & 24 & 15.62 \\
\hline SB-5 & $3,4-\mathrm{Cl}$ & 14 & NC \\
\hline SB-6 & $2-\mathrm{NO}_{2}$ & 20 & 62.48 \\
\hline SB-7 & $3-\mathrm{Cl}$ & 18 & $\mathrm{NC}$ \\
\hline SB-8 & $4-\mathrm{NO}_{2}$ & 22 & 31.24 \\
\hline SB-9 & $4-\mathrm{OCH}_{3}$ & 18 & $\mathrm{NC}$ \\
\hline SB-10 & $2-\mathrm{Cl}$ & 16 & NC \\
\hline SB-11 & $2-\mathrm{Cl}, 4-\mathrm{NO}_{2}$ & 18 & NC \\
\hline SB-12 & $3-\mathrm{NO}_{2}$ & 14 & NC \\
\hline SB-13 & $2-\mathrm{Br}$ & 16 & $\mathrm{NC}$ \\
\hline SB-14 & $4-\mathrm{F}$ & 18 & NC \\
\hline SB-15 & $2-\mathrm{OCH}_{3}$ & 18 & NC \\
\hline SB-16 & $2-\mathrm{CH}_{3}$ & 18 & NC \\
\hline Clotrimazole & - & 26 & 1.95 \\
\hline Terbinafine & - & 26 & 2.6 \\
\hline
\end{tabular}

$\mathrm{NC}=$ not calculated about 8 hours (Fig. 1). The resulting solid was filtered and washed with aqueous sodium hydroxide solution (20\%) and with an excess of water. The crude product was purified by recrystallization from ethanol to afford a compound 4-methyl-7-(2-oxo-2-phenylethoxy)-2Hchromen-2-one (3). The Schiff bases SB-1 to SB-16 were prepared by refluxed of compound (3) with different aromatic anilines in the presence of glacial acetic acid (4) in methanol. The purity of the compounds was monitored by TLC, and the structure of the compounds was deduced on the basis of spectral data. The $\mathrm{C}=\mathrm{N}$ stretching (str.) at 1,594 to $1,615 \mathrm{~cm}^{-1}$ and 5.41 to $5.58 \delta \mathrm{ppm}$ of $2 \mathrm{H}$ (singlet proton) of $-\mathrm{OCH}_{2}$ in NMR spectra of target compounds confirmed the structure of test compounds. The molecular property prediction was made for the target compounds (Schiff bases). All Schiff bases have molar refractivity under 130, except SB-12 to SB-16. The topological polar surface area (tPSA) is a measure of a molecule's hydrogen-bonding capacity, and its value should not exceed certain limits. The tPSA values for the test compounds were well within these limits (47.87-99.70). The log P values of test compounds were (4.22-6.03) within the range of standard drugs, which shows that these compounds have the potential to cross the blood-brain barrier effectively or lipophilicity nature of test compounds. The other descriptors computed include, Connolly solvent accessible surface area $\left(\mathrm{SAS}, \mathrm{A}^{2}\right)$, Connolly molecular surface area (MSA, $A^{2}$ ), Connolly solvent 
excluded volume (SEV, $\mathrm{A}^{3}$ ), ovality, molecular topological index (MTI), and wiener index (wi) for the test compounds were in the range of standard drug clotrimazole and terbinafine. The test compounds were tested for activity against $C$. albicans. The results of antimicrobial activity are shown in Table 2. It is evident from the results of the Schiff bases containing halogen atom, like bromo and nitro, at position-4 (SB-4 and SB-8), were showing the most potent antifungal activity, as compared to the other Schiff bases. It is highlighting the importance of the presence of electron-withdrawing groups in the phenyl ring. The other Schiff bases (SB-1, SB-3, and SB-6) showed the antifungal activity. Among the compound, SB-4 was showed the most potent antifungal activity in the test compounds.

The compounds having a zone of inhibition $20 \mathrm{~mm}$ or greater than $20 \mathrm{~mm}$ is considered as active.

\section{CONCLUSION}

The present study describes the synthesis and evaluation of the antifungal activity of a series of new Schiff bases. The synthesized compounds, therefore, present a new scaffold that can be used to as lead in the development of novel antifungal agents.

\section{ACKNOWLEDGEMENT}

The authors are thankful to Prof. (Dr.) M. P. Pandey, Vice-Chancellor, Mr. Sanjeev Agrawal, Registrar, and Prof. (Dr.) Navneet Verma, Dean, Pharmacy Department, IFTM University, Moradabad, U.P., India, for the kind support and providing the research infrastructure.

Authors cannot forget to thanks Prof. (Dr.) Prabhakar Gupta, Dean Academics and Prof. (Dr.) Lalit Singh, Director Pharmacy, Shri Ram Murti Smarak College of Engineering and Technology, Bareilly, U.P., India, for their kind cooperation and encouragement.

\section{REFERENCES}

1. Kumar S, Chandna M, Gupta M. Synthesis and antimicrobial activity of Schiff bases and azetidinones of 7-hydroxy-4- methyl-chromen-2one. Journal of Pharmacy Research. 2010;3(12):3010-3012.

2. Sadeghpour H, Khabnadideh S, Zomorodian K, Pakshir K, Hoseinpour $\mathrm{K}$, Javid N, et al. Design, Synthesis, and Biological Activity of New Triazole and Nitro-Triazole Derivatives as Antifungal Agents. Molecules. 2017;22:1150.

3. Kumar S, Kumar P, Sati N. Synthesis and biological evaluation of Schiff bases and azetidinones of 1-naphthol. J Pharm. Bioall. Sci. 2012;4:246-249.

4. Kumar S, Tanmoy DE. Synthesis and antimicrobial activity of Mannich bases of isatin derivatives. International Journal of Advances in Pharmaceutical Sciences. 2013;4(5):1054-1061.

5. Gupta M, Kumar S, Gupta MK. Synthesis and antimicrobial activity of some novel derivatives of 7-Hydroxy-4-Methyl Coumarin. MIT International Journal of Pharmaceutical Sciences. 2015;1(1):19-26.

6. Li Y, Zhao C P, Ma HP, Zhao MY, Xue YR, Wang XM. Design, synthesis and antimicrobial activities evaluation of Schiff base derived from secnidazole derivatives as potential FabH inhibitors. Bioorg. Med. Chem. 2013;21:3120-3126.

7. Barbuceanu SF, Ilies DC, Saramet G, Uivarosi V, Draghici C, Radulescu V. Synthesis and antioxidant activity evaluation of new compounds from hydrazinecarbothioamide and 1,2,4-triazole class containing diarylsulfone and 2,4-difluorophenyl moieties. Int. J. Mol. Sci. 2014;15:10908-10925.

8. Chazin EL, Sanches PS, Lindgren EB, Vellasco WT, Pinto LC, Burbano RM, et al. Synthesis and biological evaluation of novel 6-Hydroxy-benzo[d][1,3]oxathiol-2-one Schiff bases as potential anticancer agents. Molecules. 2015;20:1968-1983.

9. Aanad P, Patil VM, Sharma VK, Khosa RL Masand N. Schiff bases: A review on biological insights. Int. J. Drug Des. Discov. 2012;3: 851-868.

10. Aouad MR. Synthesis, characterization and antimicrobial evaluation of some new Schiff, Mannich and acetylenic mannich bases incorporating a 1, 2, 4-triazole nucleus. Molecules. 2014;19: 18897-18910.

11. Kumar S, Wahi AK, Singh R. Computational studies and preliminary pharmacological evaluation of 2-[4-(aryl substituted) piperazin1-yl] N, N-diphenylacetamides as potential antipsychotics. European Journal of Medicinal Chemistry. 2011;46:4753-4759.

12. Von Pechmann H, Duisberg C. Zeolite catalysed synthesis of coumarin derivatives. Chem. Berg. 1883;16:2119.

13. Furniss BS, Hannaford AJ, Smith PWJ, Tatechell AR. Vogel's Textbook of Practical Organic Chemistry, Longman, New York. 1989;5:1193. 